\title{
ESSAI DE CLASSIFICATION \\ DES BLASTOMYCÈTES PATHOGÈNES
}

\section{Par Masao OTA}

Ancien professeur de dermatologie à la faculté de médecine de Moukden

On sait que la définition des blastomycètes est très vague. On classe dans ce groupe non seulement des champignons parasites appartenant aux genres Cryptococcus, Monilia et à la famille des Saccharomycètes, mais aussi parfois des formes du genre Mycoderma. Je crois préférable de ne donner le nom de blastomycètes qu'aux champignons qui présentent des blastospores comme organes de sporulation.

Les parasites de ce groupe, actuellement connus, appartiennent aux genres suivants :

\section{A. - Saccharomycètes}

\section{Genres : Saccharomyces.}

- Willia.

- Debaryomyces.

\section{B. - Autres blastomycètes}

Genre Cryptococcus... $\left\{\begin{array}{l}a . \text { Gryptococcus ne se présentant } \\ \text { jamais sous la forme filamenteuse. } \\ \text { des formes filamenteuses. } \\ \text { Quelques espèces peuvent être considé- } \\ \text { rées comme des formes de transition } \\ \text { au genre Monilia. }\end{array}\right.$

\section{Genre Monilia.}

Les blastomycètes qui appartiennent à la famille des Saccharcmycètes sont en très petit nombre et mycologiquement bien définis. Au contraire, la plupart des autres blastomycètes pathogènes sont des champignons qui ne produisent pas d'asques ; ils sont d'ordinaire très mal étudiés au point de vue mycologique. Dans l'état actuel de la science, l'identification des espèces est très difficile. En outre, les noms génériques diffèrent suivant les auteurs. On trouve Annales de Parasitologie, T. II, $\mathrm{N}^{\circ}$ 1. - Janvier 1924, p. 34. 
les dénominations suivantes : Cryptococcus, Torula, Saccharomyces, Blastomyces, Atelosaccharomyces, Parasaccharomyces, Zymonema, Parendomyces, Pityrosporum, Dermatophyton, Histoplasma, Oospora, Monilia, Oidium, etc.

Depuis deux ans, j'ai recueilli une quarantaine d'espèces de blastomycètes considérées comme pathogènes. J'ai publié une étude (Ota, 1923) sur les espèces de cette collection qui produisent des asques. Dans la suite, j'en ai reçu encore une espèce que je décrirai ci-dessous.

Je voudrais en même temps donner une description des blastomycètes considérés comme pathogènes, qui ne produisent pas d'asques et dont l'origine est bien connue. Cette description est limitée à leur morphologie. Quant à leur étude complète, je l'entreprendrai plus tard, si l'occasion me le permet. En étudiant la morphologie de ces espèces, on est conduit à faire quelques groupements et je crois qu'on pourrait les utiliser ultérieurement pour arriver à une classification.

\section{I. - Genre Debaryomyces}

Parmi les Debaryomyces considérés comme pathogènes, on connaissait seulement deux espèces : D. Nadsoni Guilliermond et Péju, 1911, provenant d'un cas de sycosis et D. Klöckeri Guilliermond et Péju, 1920, provenant d'un cas d'angine. Plus tard, j'ai constaté que les levures de Hudelo, de Léopold, de Lundsgaard, de Ladegaard et de Hildegaard appartiennent aussi à ce genre.

Dernièrement, le $\mathrm{D}^{r}$ Langeron m'a communiqué quelques cultures de levures provenant d'épidermomycoses, parmi lesquelles j'ai trouvé une nouvelle espèce de ce genre.

Debaryomyces Burnieri n. sp.

1. Origine. - Cette espèce a été isolée par le $\mathrm{D}^{\mathrm{r}}$ Burnier à l'Hôpital Saint-Louis chez une femme atteinte d'une épidermomycose d'aspect eczémateux.

2. Forme des cellules. - Sur moût de bière gélosé, au bout d'un jour, à $25^{\circ}$, les éléments sont généralement arrondis ou ovoïdes. Leur diamètre est de 4 à $5 \mu$. Quelquefois, il y a des cellules ovoïdes qui mesurent de 8 à $10 \mu$ sur $5 \mu$, ou même des cellules allongées, dont la longueur atteint $15 \mu$ ou plus. Ces cellules sont tantôt isolées, tantôt soudées deux à deux, tantôt groupées en chapelets. 
Les éléments possèdent de grandes vacuoles et parfois des granulations graisseuses. Ordinairement, il n'y a qu'un seul granule très petit dans les cellules d'une culture de 24 heures. La membrane des cellules est mince ; elle ne montre pas de double contour (fig. 1, a).

Sur les mêmes milieux, au bout de 7 jours, les cellules qui forment des chapelets sont très peu visibles. Elles sont isolées ou groupées deux à deux, mais souvent une grande cellule est entourée d'autres plus petites. La dimension des cellules est à peu près la même que

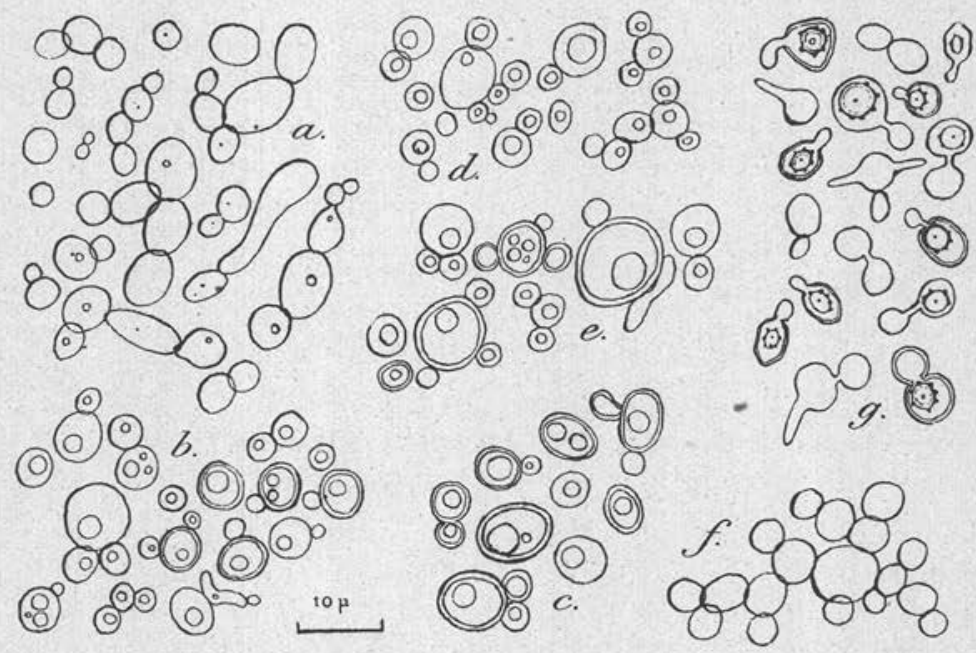

Fıg. 1. - Debaryomyces Burnieri. a, culture sur moût gélosé au bout d'un jour à $25^{\circ} ; b$, la même culture au bout d'une semaine ; $c$, la même au bout d'un mois; $d$, culture sur carotte au bout d'un jour à $25^{\circ}$; $e$, la même culture au bout d'un mois ; $f$, culture en cellule sur moût liquide, au bout d'un jour ; $g$, culture sur gélose de Gorodkowa, au bout de 3 jours.

celle des cellules d'une culture àgée d'un jour, mais les granules augmentent de volume, la membrane s'épaissit et montre souvent un double contour (fig. $1, b$ ).

Au bout d'un mois, les cellules deviennent en général plus volumineuses et les granules de graisse croissent aussi. Le double contour des membranes est plus net (fig. $1, c$ ).

Les cellules des cultures sur carotte sont d'ordinaire arrondies et elles possèdent un granule assez visible déjà au bout d'un jour. Leur membrane est relativement épaisse. Elles sont solitaires ou groupées : on trouve souvent une grande cellule entourée d'autres plus petites. On n'a pas trouvé de chapelets de cellules (fig. 1, d). Sur les mêmes milieux, au bout d'un mois, les cellules sont ordinai- 
rement très grandes. Il y en a parfois qui ont $12 \mu$ de diamètre. De grandes cellules groupent de coutume une ou plusieurs cellules plus petifes autour de leur paroi. Elles présentent parfois un vestige de la membrane d'un asque (?). Ces cellules sont, pour la pluvart, pourvues d'une membrane assez épaisse (fig. $1, e$ ).

On trouve sur le moût de bière liquide, au bout d'un jour, une formation abondante de chapelets composés de cellules nombreuses (fig. 1, $f$ ). Quelques jours plus tard, le nombre des cellules qui composent les chapelets diminue.

3. Aspect macroscopique de la végétation sur moût de bière. La levure forme un dépôt blanchâtre au fond du tube au bout de 24 heures. Vers le dixième jour, elle forme un anneau très mince sur la paroi du tube; cet anneau s'épaissit un peu au bout de 40 jours et prend une couleur jaunêtre.

4. Aspect macroscopique des cultures sur gélose au moût de bière. - Les colonies sont d'un blanc crayeux, leur surface est lisse et ne présente ni plis ni aspect granuleux. Les bords sont nets.

5. Sexualité et sporulation. - La formation des asques à lieu parfois sur moût gélosé, mais elle est plus facile sur gélose de Gorodkowa. J'ai trouvé des asques dans les cultures dès le troisième jour.

La copulation s'effectue généralement entre une cellule relative. ment grande et une cellule beaucoup plus petite. Plus rarement, elle a lieu entre deux cellules à peu près de même grandeur. En tous cas, les deux cellules s'attachent directement par leur paroi ou par un bec plus ou moins long.

Les asques sont ronds, ovoïdes ou parfois hexagonaux ; leur diamètre est de 4 à $7 \mu$. Les ascospores sont arrondies ou elliptiques et mesurent de 2 à $4 \mu$ de diamètre. Elles présentent quelquefois un double contour. Leur paroi est ornée d'un petit nombre de protubérances verruqueuses. Ces protubérances sont ondinairement très aplaties et ne présentent jamais d'épines pointues. Parfois la paroi est lisse. Les ascospores renferment un ou plusieurs granules graisseux très petits (fig. $1, g$ ).

Les levures pathogènes du genre Debaryomyces étaient peu connues jusqu'à ces dernières années ; actuellement leur nombre augmente, mais les espèces ne possèdent pas généralement une virulence très grande. 


\section{II. - Genre Cryptococcus}

Les levures qui ne forment pas d'asques sont classées dans les genres Torula Turpin ou Cryptococcus Kützing. Le genre Torula Turpin renferme des champignons tout à fait différents de ceus qui sont rangés dans le genre Torula Persoon. Ce dernier est très mal défini et depuis quelque temps une partie des espèces qu'on y avait fait entrer sont considérées comme appartenant au genre Scopulariopsis Bainier. Le nom de Torula Turpin est employé actuellement tout à fait dans le même sens que Cryptococcus Kützing. Il serait trop artificiel de classer les levures anascoporées pathogènes parmi les Cryptococcus et celles qui ne sont pas pathogènes parmi les Torula.

Les espèces du genre Cryptococcus ont une grande variété de caractères morphologiques. On classe quelquefois dans ce genre des blastosporés pourvus d'éléments mycéliens très développés qui mériteraient d'être nommés Monilia. Il serait donc nécessaire de faire une révision de ces espèces et de les grouper d'après leurs types morphologiques.

J'ai recueilli une trentaine de Cryptococcus considérés comme pathogènes. Les espèces dont l'origine est connue sont les suivantes :

\section{A. - Gryptococcus ne prenant jamais la forme filamenteuse}

Type I. - Levures rondes, ovoïdes ou elliptiques, relativement grandes, ordinairement solitaires ou sie groupant deux à deux, pourvues d'une membrane assez épaisse et présentant un double contour très net. La couleur de leurs cultures devient ocracée, grisâtre quand elles vieillissent. Ces espèces ont une grande virulence.

1. Cryptococcus hominis (Busse) Vuillemin.

2. Torula histolytica Stoddard et Cutler, 1916 (cas de Freeman et Weidman).

3. En outre, le Cryptococcus colombi Castellani, conservé dans la mycothèque du $\mathrm{D}^{\mathrm{r}}$ Sabouraud et dont l'origine m'est inconnue, appartient à ce groupe.

4. Une levure, conservée dans la même mycothèque sous l'étiquette de "levure de Binot ", est probablement le Saccharomyces Blanchardi Guiart, 1906 ; cette levure a perdu la capacité de former des asques, comme Binot l'avait remarqué déjà, mais elle montre nettement les caractères morphologiques de ce groupe. Si cette espèce était vraiment le Saccharomyces Blanchardi, ce serait un bon argu- 
ment pour considérer les Cryptococcus comme une forme avortée de Saccharomyces.

TyPE II. - Levures rondes, ovoïdes ou un peu allongées, ordinai rement solitaires, ou se groupant deux à deux, ou formant parfois des chapelets, qui, dans les cultures, contrairement aux espèces précédentes, ont une membrane avec un double contour beaucoup moins net. La couleur de leurs cultures est ordinairement blanc-grisâtre.

Type III. - Comme le type II, mais la couleur des colonies est rose ou rouge.

5. Cryptococcus mena Fontoynont et Boucher.

Type IV. - Levures de dimension très petite, dont la membrane est mince et ne montre pas de double contour net. La couleur des colonies est blanc-grisâtre.

6. Cryptococcus de Burnier, cas d'S.

7. Un autre Cryptococcus, qui a été isolé par le $\mathrm{D}^{r}$ Burnier dans un cas d'epidermomycose chez M. H. ( $\mathrm{N}^{\circ} 22$ du $\mathrm{D}^{r}$ Langeron), est très semblable au précédent.

\section{B. - Cryptococcus pouvant prendre la forme filamenteuse}

Ces levures constituent un passage au type Monilia.

1. Cryptococcus de Burnier, cas de C.

2. Cryptococcus de Favre.

3. Cryptococcus Copellii Neveu-Lemaire.

4. Cryptococcus de Skutelzky.

5. Cryptococcus de Kartulis.

\section{PREMIER GROUPE}

Cryptococcus sans éléments filamenteux

TYPE I. - Gryptococcus à cultures ocracées

Cryptococcus hominis (Busse) Vuillemin, 1901

Syn. - Saccharomyces sp. Busse, 1894. - Atelosaccharomyces Busse Buschki de Beurmann et Gougerot, 1909.

1. Origine. - Busse a obtenu cette espèce dans une inflammation purulente sous-périostée du tibia chez une femme.

2. Forme des cellules. - Les cellules sur gélose au moùt de bière, au bout d'un jour, à $25^{\circ}$, sont rondes ou ovoïdes. Leur diamètre est de 4 à $10 \mu$. Quand elles sont ovoïdes, elles mesurent 8 à $10 \mu$ sur 6 à $7 \mu$. On voit souvent des cellules dont la paroi présente une ponc- 
tuation. Leur membrane est en général épaisse, mais le double contour n'est pas encore très net. Elles contiennent une ou plusieurs vacuoles et rarement des granulations graisseuses. Les cellules sont solitaires ou accolées à un élément plus petit. On ne trouve ni amas ni chaînettes (fig. $2, a$ ).

Sur les mêmes milieux, au bout d'une semaine, les cellules deviennent en général plus grandes. On rencontre souvent des éléments de $10 \mu$ de diamètre. La membrane devient plus épaisse et présente un double contour bien net. Les granulations graisseuses augmentent

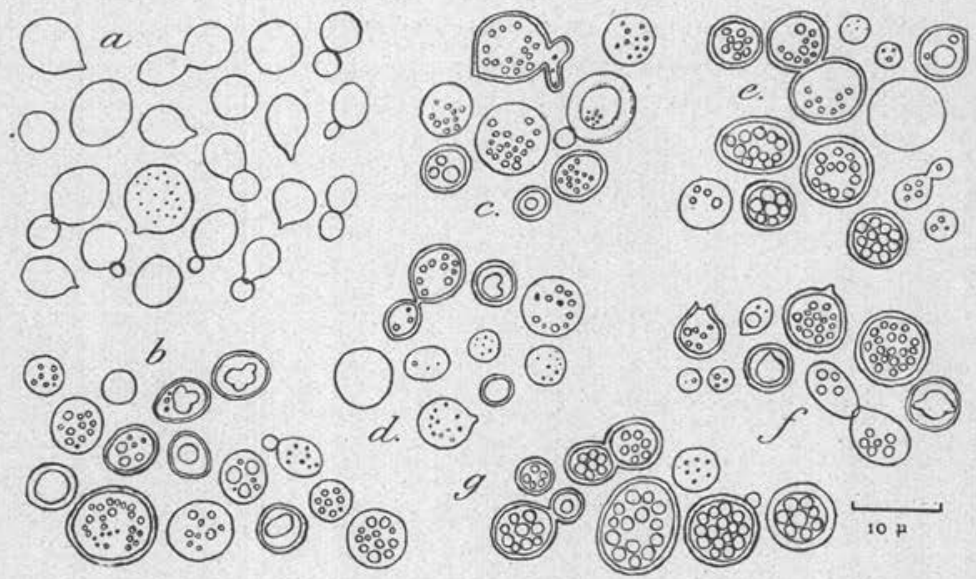

Fig. 2. - Cryptococcus hominis. $a$, culture sur moût gélosé au bout d'un jour à $25^{\circ}$; $b$, la même au bout d'une semaine; $c$, la même au bout d'un mois ; $d$, culture sur carotte à $25^{\circ}$ au bout d'un jour; $e$, la même au bout de 4 jours ; $f$, la même au bout d'une semaine; $g$, la mềme au bout d'un mois.

aussi de volume : tantôt on rencontre un granule volumineux, tantôt plusieurs plus petits (fig. 2, $b$ ).

Au bout d'un mois, les caractères morphologiques des cellules sont à peu près les mêmes. Toutefois, on voit apparaitre des éléments très réfringents dont la membrane très épaisse atteint souvent plus d'un micron. Elle donne un aspect particulier à ce groupe de levures (fig. $2, e$ ).

Sur carotte, au bout d'un jour, à $25^{\circ}$, les cellules sont pour la plupart arrondies et possèdent une membrane assez épaisse à double contour. Elles contiennent en plus des vacuoles un granule de graisse assez volumineux ou plusieurs petits (fig. 2, d). Au bout de 4 jours, le double contour de la membrane des cellules devient encore plus net. Les granules graisseux s'agrandissent aussi (fig. 2, e). 
Les caractères morphologiques des cellules, au bout d'une semaine, sont semblables à ceux des cellules de 4 jours (fig. $2, f$ ).

Au bout d'un mois, la forme des cellules est très caractéristique. Elles sont ordinairement volumineuses et pourvues d'une membrane très épaisse. Elles contiennent de grosses granulations groupées et serrées les unes contre les autres (fig. 2, $g$ ).

La levure ne forme ni amas ni chaînette, même dans les cultures en cellule sur moût de bière liquide. Elle ne produit pas d'asques sur gélose de Gorodkowa.

3. Aspect macroscopique de la végétation sur moût de bière. Au bout de deux semaines la levure forme au fond du tube un dépôt gris-jaunâtre assez épais, ainsi qu'un anneau très mince sur la paroi du tube, au-dessus de la surface.

4. Aspect macroscopique des cultures sur gélose au moût de bière. - Colonies épaisses, d'abord blanches puis jaunâtres ; la surface est lisse et les bords sont nets.

5. Caractères biochimiques. - D'après Sasagawa, cette levure provoque la formation d'un acide, mais pas de gaz avec le dextrose, le levulose, le mannose et le galactose ; elle n'a aucune action fermentative sur le saccharose, le maltose, le lactose et le raffinose.

\section{Torula histolytica Stoddard et Cutler, 1916}

1. Origine. - Cette levure a été isolée chez un homme atteint d'une méningite plastique et d'une infiltration cystique de la substance grise. La culture première a été obtenue par l'ensemencement du liquide céphalo-rachidien sur gélose au sang. Les cultures secondes ont été obtenues facilement sur les milieux ordinaires. Cette espèce est pathogène pour les cobayes.

2. Forme des cellules. - Sur moût de bière gélosé, au bout d'un jour, à $25^{\circ}$, les cellules sont solitaires ou groupées deux à deux, une grande à côté d'une petite. Parfois on en trouve deux de même grandeur accolées. La plupart des cellules sont arrondies ou ovoïdes. Elles présentent quelquefois de courts piquants sur un ou deux points. Leur diamètre est en moyenne de 5 à $8 \mu$. Il y en a beaucoup qui sont plus petites. Parfois il y en a aussi dont le diamètre atteint $10 \mu$.

Leur membrane est relativement épaisse, elle ne montre pas de double contour net le premier jour. Elles renferment une ou plu. sieurs vacuoles et quelquefois des granulations graisseuses (fig. $3, a$ ).

Au bout d'une semaine, les éléments restent solitaires : leur forme 
et leur diamètre sont à peu près les mêmes qu'au bout d'un jour. La membrane s'épaissit et montre un double contour assez net ; des granulations graisseuses apparaissent (fig. $3, b$ ).

Au bout d'un mois, les cellules présentent un aspect très frappant à cause de leur membrane épaisse et très réfringente. Son épaisseur est ordinairement de $1 \mu$ et parfois elle atteint $2 \mu$. Le double contour est très net. Les cellules renferment un ou plusieurs granules volumineux; elles augmentent généralement de volume. On voit parfois des éléments irréguliers (fig. $3, c$ ).

Sur carotte, au bout d'un jour, à $25^{\circ}$, les cellules ont les mêmes
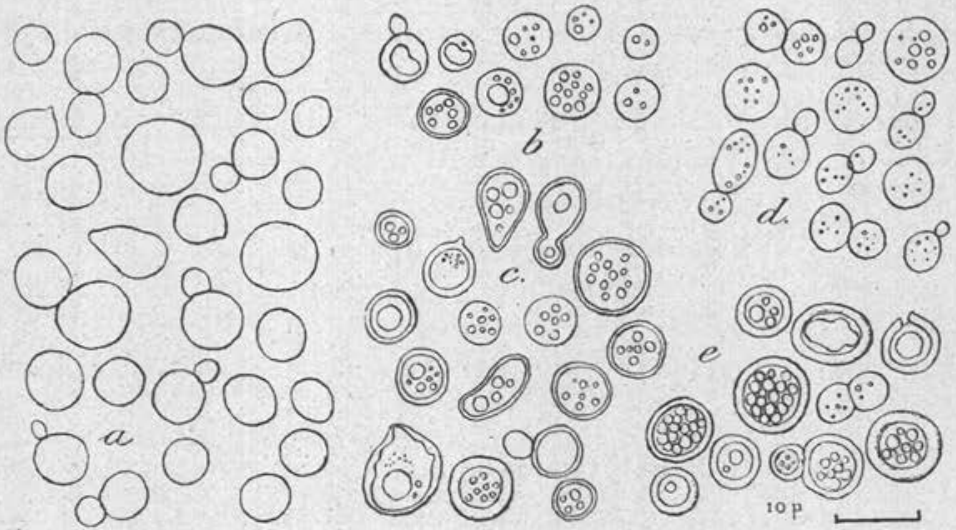

Fıg. 3. - Torula histolytica. $a$, culture sur moût gélosé à $25^{\circ}$ au bout d'un jour ; $b$, la même au bout d'une semaine; $c$, la même au bout d'un mois ; $d$, culture sur carotte à $25^{\circ}$ au bout d'un jour; $e$, la méme au bout d'un mois.

caractères que sur moût gélosé à la même date, mais elles contiennent des granules plus nets (fig. $3, d$ ). Au bout d'une semaine, les caractères morphologiques n'ont pas beaucoup changé. Les granules se sont agrandis un peu et des cellules dont la membrane a un double contour commencent à apparaître. Au bout d'un mois, la forme des cellules est très caractéristique. Elles sont d'ordinaire arrondies ou parfois un peu allongées, solitaires ou quelquefois groupées deux à deux. Leur membrane est en général plus épaisse que dans les cultures sur moût gélosé de même date et les granules de graisse sont aussi plus grands. Les cellules ont souvent à l'intérieur un grand granule irrégulier. Il y a aussi des cellules dont la membrane est brisée sur un point. Tous ces caractères morphologiques donnent à cette espèce, comme à l'espèce précédente, un aspect particulier qui peut servir à distinguer ce groupe (fig. $3, e$ ). 
Il ne se forme pas d'asques, même sur gélose de Gorodkowa.

3. Aspect macroscopique de la végétation sur moût de bière. D'après Freeman et Weidman, la levure forme un nuage dans le milieu et un anneau très délicat sur la paroi du tube au-dessus de la surface du liquide. Au bout de deux semaines l'anneau s'épaissit et le milieu est devenu clair. Un dépôt se forme au fond du tube.

4. Aspect macroscopique des cultures sur moût gélosé. - D’après Freeman et Weidman, la croissance des colonies est très rapide. Le bord des colonies est net, il s'élève au-dessus de la surface du milieu. Sa couleur est d'abord jaunâtre et devient ocre foncé après 4 semaines. Cette couleur se développe plus rapidement dans les cultures secondaires, c'est-à-dire du $7^{\circ}$ au $10^{\circ}$ jour. Quand les cultures en tube sont âgées de 6 ou 8 semaines, ou même moins si le milieu sèche, la couleur devient ocracée brunâtre.

Dans la culture géante sur gélose glycosée, le changement de couleur s'effectue plus rapidement. La couleur est ocre au quatrième jour et devient ocre brunâtre à la quatrième semaine. La colonie est de consistance pâteuse et sa largeur n'est que d'un centimètre.

5. Action sur les sucres. - D'après les mêmes auteurs, cette levure produit un acide avec le saccharose, le glycose, le maltose et la dextrine, mais non avec le lactose et l'inuline. Il n'y a pas de production de gaz avec le glycose, le maltose, le saccharose, le lactose, le galactose, l'inuline et la dextrine.

6. Position systématique. - Freemand et Weidman ont identifié cette levure avec la levure pathogène de Frothingham, isolée par Stoddard et Cutler. Ils l'ont donc nommée Torula histolytica. Elle montre quelques ressemblances avec la levure de Flu et Wœensdreght. J'ai trouvé une grande ressemblance entre cette espèce et la levure précédente. Leur seule différence est dans l'action biochimique sur les sucres.

\section{TYPE II. - Gryptococcus à cultures blanchâtres}

Cryptococcus de Gougerot et Gancea

1. Origine. - Cette espèce a été isolée par Gougerot et Gancea en 1914 d'un cas d'épidermomycose des plis inguinaux et conservée dans la mycothèque du $\mathrm{D}^{\mathrm{r}}$ Sabouraud.

2. Forme des cellules. - Les cellules sur moût gélosé, au bout d'un jour, à $25^{\circ}$, sont généralement ovoïdes, quelquefois arrondies ou allongées. Elles sont solitaires ou groupées deux à deux, mais parfois elles forment des amas composés d'une grande cellule entourée 
de petites. Ces cellules ont une membrane mince qui ne présente pas de double contour, elles renferment des vacuoles et quelquefois de petits granules (fig. $4, a$ ).

$\mathrm{Au}$ bout de trois jours les cellules sont pour la plupart solitaires, mais il y en a qui se relient deux à deux par un bec allongé, rappelant l'aspect de la copulation de quelques levures ascosporées (fig. $4, b$ ). Pourtant aucune formation d'asques n'a été observée dans aucun milieu, même sur gélose de Gorodkowa.

Au bout de deux semaines, les granules s'agrandissent en général. Au bout d'un mois, les cellules deviennent plus volumineuses et
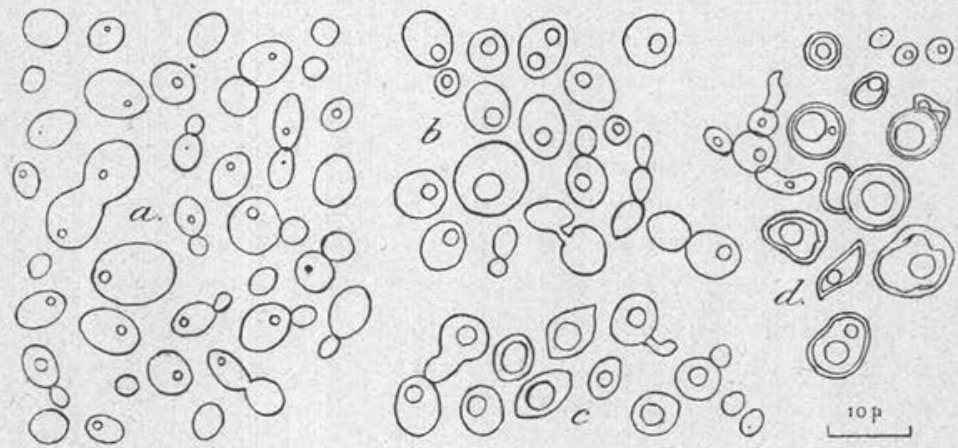

Fig. 4. - Cryptococcus de Gougerot et Gancea. $a$, culture sur moût gélosé à $25^{\circ}$ au bont d'un jour; $b$, la même au bout de 3 jours; $c$, la même au bout de 2 semaines; $d$, la même au bout d'un mois.

présentent une membrane assez épaisse avec un double contour net. Elles sont ordinairement solitaires et arrondies, mais il y en a dont la forme est irrégulière et qui sont pourvues d'une membrane ridée. Les cellules contiennent d'ordinaire un granule volumineux (fig. $4, d$ ).

3. Aspect macroscopique de la végétation sur moût de bière. La levure forme un anneau grisêtre très mince sur la paroi du tube et un dépôt peu abondant.

4. Aspect macroscopique des cultures sur gélose au moût de bière.La colonie est épaisse, son bord est net, sa surface est lisse, mais on peut y observer des plis très faibles. La couleur est d'abord grisâtre, plus tard elle devient un peu jaunâtre.

\section{Cryptococcus de Burnier, cas Th.}

1. Origine. - Cette levure a été isolée par le $\mathrm{D}^{\mathrm{r}}$ Burnier d'un cas d'épidermomycose ( $\mathrm{N}^{\circ} 22 \mathrm{du} \mathrm{D}^{\mathrm{r}}$ Langeron). 
2. Forme des cellules. - Sur moût gélosé, au bout d'un jour, à $25^{\circ}$, la forme des cellules est ovoïde ou légèrement allongée. Elles sont solitaires ou groupées deux à deux ou quelquefois en chaînettes composées d'un petit nombre de cellules. Leur diamètre est en moyenne de 6 à $8 \mu$ sur 4 à $5 \mu$.

La membrane est mince, sans double contour. Il y a à l'intérieur des vacuoles, mais d'ordinaire pas de granules (fig. $5, a$ ).

Au bout d'une semaine, les cellules s'agrandissent notablement : on en trouve souvent qui mesurent $12 \mu$ sur $10 \mu$. Elles sont arrondies ou elliptiques. Leur membrane est assez épaisse, et chez quelques-

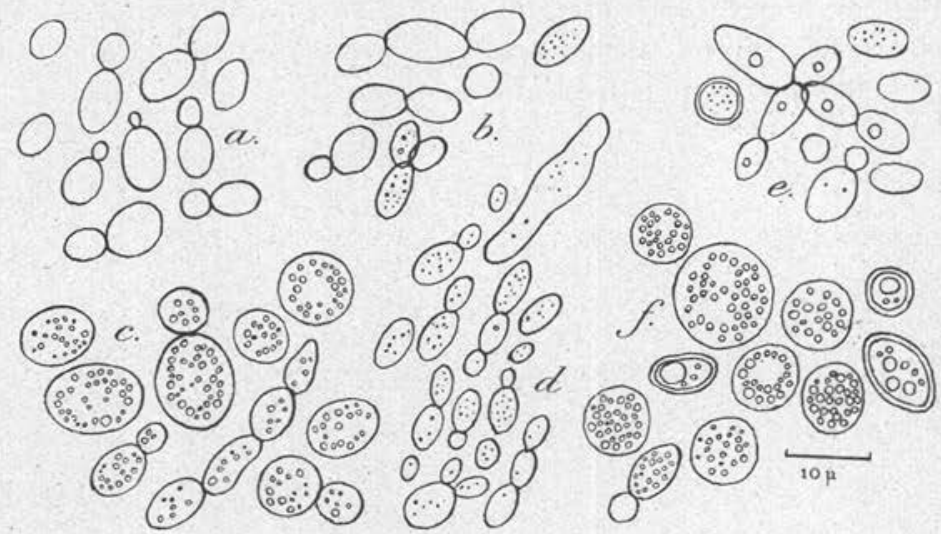

FIg. 5. - Cryptococcus de Burnier (malade Th.). $a$, culture sur moût gélosé à $25^{\circ}$ au bout d'un jour; $b$, la même au bout d'une semaine; $c$, la même au bout d'un mois; $d$, culture sur carotte à $25^{\circ}$ au bout d'un jour; $e$, la même au bout d'une semaine; $f$, la même au bout d'un mois.

unes, surtout sur carotte, on voit un double contour très net (fig. $5, e, f$ ).

On n'observe jamais de formation d'asques sur aucun milieu.

3. Aspect macroscopique de la végétation sur moût de bière. La levure forme un anneau très mince et un dépôt au fond du tube.

4. Aspect macroscopique des cultures sur gélose au moût de bière. La culture est d'un blane grisâtre passant au jaunâtre, sa surface est lisse et humide, son bord est net.

Type III. - Gryptococcus à cultures rouges ou roses

Cryptococcus mena Fontoynont et Boucher, 1923

1. Origine. - D'après Fontoynont et Boucher, cette levure est une espèce pathogène assez répandue à Madagascar ; ils ont observé en 
peu de temps trois eas de blastomycoses causées par cette espèce : dans une ulcération d'un orteil, dans des lésions ulcéreuses dermoépidermiques des jambes, d'un pied et de la face et enfin dans une énorme ulcération de la partie antérieure du thorax, présentant l'aspect d'un abcès froid tuberculeux.

Cette levure produit la réaction positive de la fixation du complément. Il semble qu'il soit un peu pathogène pour les rats, les pigeons et les lapins. Elle est conservée au Laboratoire de Parasitologie de la Faculté de médecine de Paris.

2. Forme des cellules. - Les cellules, dans les cultures sur gélose au moût de bière, au bout d'un jour, à $25^{\circ}$, sont ovoïdes ou elliptiques, parfois rondes. Celles qui sont rondes ont un diamètre de 4 à $5 \mu$; celles qui sont elliptiques mesurent de 5 à $8 \mu$ sur 4 à $5 \mu$.

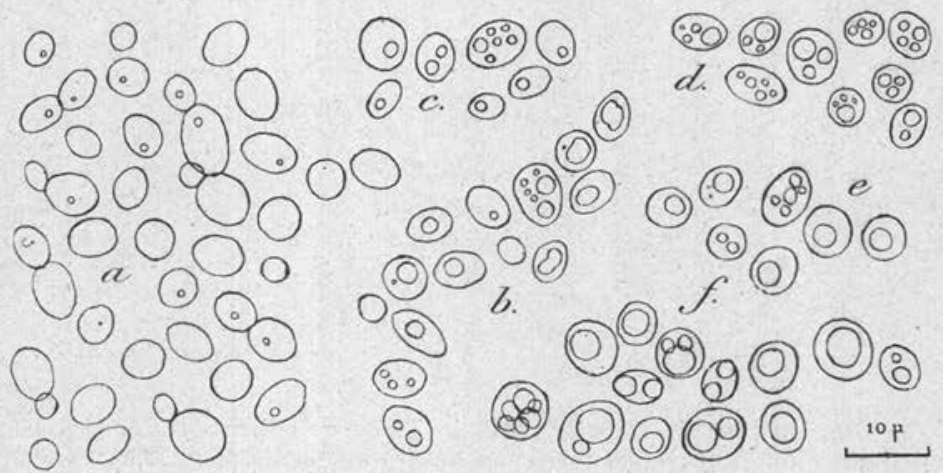

Fig. 6. - Cryptococcus mena. $a$, culture sur moût gélosê à $25^{\circ}$ au bout d'un jour; $b$, la même au bout d'une semaine ; $c$, culture sur carotte à $25^{\circ}$ au bout d'un jour ; $d$, la même au bout de 4 jours ; $e$, la même au bout d'une semaine ; $f$, la même au bout d'un mois.

La membrane est mince et ne montre pas de double contour net. Ces éléments contiennent des vacuoles et parfois un petit granule à l'intérieur. Ils sont ordinairement solitaires, mais on trouve aussi des chaînettes composées d'un petit nombre de cellules (fig. 6, a).

Au bout d'une semaine, les cellules sont en général solitaires ; elles ont à l'intérieur un grand granule rond ou de forme in régulière ou plusieurs petits granules peu réfringents (fig. $6, b$ ).

Les caractères morphologiques des cellules, au bout d'un mois, sont à peu près les mêmes qu'au bout d'une semaine (fig. $6, c$ ).

Sur carotte, au bout d'un jour ou d'une semaine, la forme des cellules est pareille à celle des cellules sur moût gélosé de même date, seulement les granules sont généralement plus volumineux (fig. 6, $d, e$ ). 
Au bout d'un mois, les cellules sont pour la plupart solitaires et présentent une forme beaucoup plus typique. Elles sont d'ordinaire arrondies et renferment un ou plusieurs granules assez volumineux. Quelques levures présentent une membrane avec un double contour assez net (fig. $6, f$ ).

3. Aspect macroscopique de la végétation sur moût de bière. La levure forme au bout d'un jour, au fond du tube, un dépôt rose qui s'épaissit après un mois. En outre on observe un anneau très faible au bout de deux semaines.

4. Aspect macroscopique des cultures sur moût gélosé. - La culture est d'une consistance de pommade et d'une couleur rose qui devient plus foncée après quelques semaines. La surface est lisse et les bords sont nets.

5. Caractères biochimiques. - D'après Fontoynont et Boucher, cette levure liquéfie la gélatine. Son action fermentative n'a pas été étudiée.

6. Températures optima et limite. - D'après ces deux auteurs, la température optima semble être située entre 18 et $25^{\circ}$. A $37^{\circ}$ la levure se développe, mais sa couleur rose n'est plus aussi marquée. Elle n'est pas tuée par 6 heures de chauffage à $60^{\circ}$ mais le pigment rose est presque complétement détruit. Elle est tuée si on trempe le tube de culture pendant deux minutes dans de l'eau en ébullition $\left(95^{\circ}\right)$.

7. Considérations générales. - Cette espèce se différencie du Saccharomyces granulatus par l'absence de reliefs granuleux sur la membrane et par la non-formation d'asques. D'après Fontoynont et Boucher, elle a une grande ressemblance avec Cryptococcus ruber.

TYPE IV. - Gryptococcus très petits à cultures grisâtres Cryptococcus de Burnier, cas S.

1. Origine. - Le $\mathrm{D}^{\mathrm{r}}$ Burnier a isolé cette espèce d'un cas d'épidermomycose ( $\mathrm{N}^{\circ} 29$ du $\mathrm{D}^{\mathrm{r}}$ Langeron).

2. Forme des cellules. - Les cellules sur moût de bière, au bout d'un jour, à $25^{\circ}$, sont d'ordinaire ovoïdes ou peu allongées, rarement arrondies. Elles ont quelquefois les deux extrémités un peu pointues. Leurs dimensions atteignent souvent $4 \mu$ sur $2 \mu$, ou $5 \mu$ sur $2 \mu, 5$. On voit rarement des cellules mesurant $6 \mu$ sur $5 \mu$. Ces cellules sont solitaires ou groupées deux à deux ; leur membrane est mince, sans double contour. Elles renferment parfois un ou deux granules très petits (fig. $7, a$ ). Au bout d'une semaine, le granule devient un peu plus volumineux (fig. $7, b$ ). 
Au bout d'un mois, les cellules s'agrandissent en général, elles sont d'ordinaire solitaires. On observe souvent des éléments dont la membrane est assez épaisse et montre un double contour plus ou moins net (fig. $7, c$ ).

Sur carotte, au bout d'un jour, les cellules sont pour la plupart arrondies et solitaires. On observe souvent le commencement du bourgeonnement (fig. $7, d$ ).

Au bout d'un mois, les cellules deviennent généralement plus volumineuses. On trouve quelquefois des cellules rondes dont le diamètre mesure $7 \mu$.

J'ai observé une fois, sur gélose de Gorodkowa, des cellules allon-

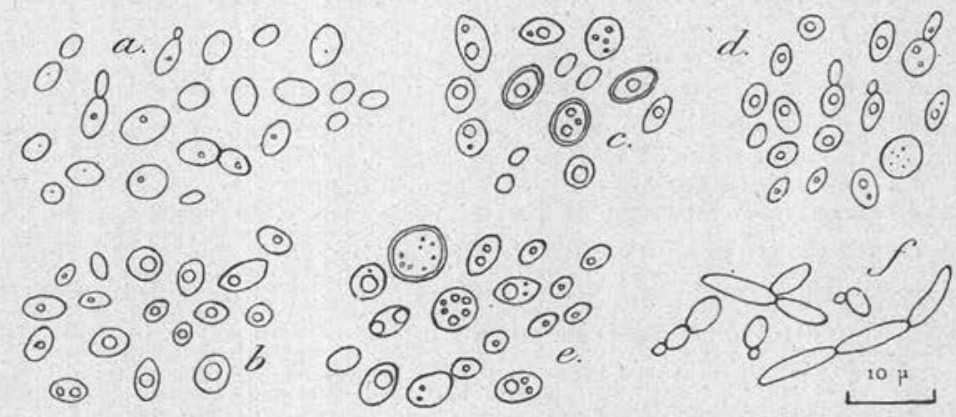

Fı́. 7. - Cryptocsccus de Burnier (malade S.). $a$, culture sur moût gélosé à 25。 au bout d'un jour; $b$, la même au bout d'une semaine; $c$, la même au bout d'un mois ; $d$, culture sur carotte à $25^{\circ}$ au bout d'un jour ; e, la même au bout d'un mois ; $f$, culture sur gélose de Gorodkowa au bout de 3 jours.

gées, mesurant $13 \mu$ sur $3 \mu$, qui formaient des chaînettes composées de trois ou quatre éléments. Je n'ai vu aucune formation d'asque sur ce milieu (fig. 7, $f$ ).

Sur bouillon maltosé au bout de deux jours, je n'ai vu que des cellules ovoïdes ou elliptiques.

3. Aspect de la végétation sur moût de bière liquide. - La culture en tube présente, au bout de deux semaines, un dépôt assez épais et un anneau faible, à contour interrompu.

4. Aspect des cultures sur moût gélosé. - La culture de deux semaines présente des colonies de couleur crême ou grisâtre. Leur surface est lisse, brillante et humide. Les bords sont nets.

5. Considérations générales. - Ce groupe des levures ressemble, par sa petite taille, au genre provisoire de Sabouraud : Pityrosporum. Mais, d'après Dold, Pityrosporum Malassezi Sabouraud, 1895 (= Saccharomyces ovalis Bizzozero, 1882) est un champignon voisin du genre Mycoderma. 


\section{DEUXIE்ME GROUPE}

\section{Cryptosoccus formant des filaments}

Les levures de ce groupe se composent pour la plupart de cellules arrondies, ovoïdes ou un peu allongées, qui s'accroissent par bourgeonnement et en même temps de longs filaments, ou ébauches de mycélium. L'élément filamenteux est ordinairement en petite quantité et rudimentaire. Il existe surtout au début des cultures et disparaît peu à peu, en se transformant en cellules solitaires et peu allongées. Il y a pourtant dans cé groupe des formes de transition et quelques espèces ressemblent beaucoup au groupe Monilia. Je les indiquerai dans la description des espèces.

De Beurmann et Gougerot ont divisé les levures pathogènes anascosporées en deux groupes : Atelosaccharomyces et Parasaccharomyces. Le premier concorde avec mon groupe A (types I, II, III, IV) et le deuxième avec mon groupe B. Ils ont supposé que les Atelosaccharomyces sont des Saccharomyces sans formation d'asques.

Cette définition est insuffisante puisque beaucoup d'espèces de Saccharomyces, par exemple S. cerevisiæ, S. pastorianus, S. maxianus présentent non seulement des cellules rondes ou ovoïdes, mais des filaments plus ou moins remarquables. Leur Parasaccharomyces est donc aussi une forme anascosporée de Saccharomyces. La légère différence qui existe entre les formes des cellules de ce groupe n'est pas suffisante pour permettre l'établissement de deux genres; elle peut servir seulement pour subdiviser un même genre.

Je voudrais ne conserver pour les champignons du groupe des Blastomycètes que deux genres : Cryptococcus (= Torula Turpin) et Monilia. Mais, comme je vais l'exposer, la distinction de ces deux genres est quelquefois très incertaine car il y a beaucoup de formes de transition entre eux.

\section{Levure de Burnier, cas de $\mathrm{C}$.}

Cette levure est l'espèce la plus simple de ce groupe ; son élément filamenteux est composé de cellules allongées qui sont très facilement dissociables. Les filaments ne montrent pas de type oïdien.

1. Origine. - Cette espèce a été isolée par le $\mathrm{D}^{r}$ Burnier dans un cas d'śpidermomycose ( $\mathrm{N}^{\circ} 30$ du $\mathrm{D}^{r}$ Langeron).

2. Forme des cellules. - Les cellules, sur moût gélosé, aù bout d'un jour, à $25^{\circ}$, sont ovoïdés ou légèrement allongées, mais souvent rondes. Leur dimension est en moyenne de $8 \mu$ sur $5 \mu$. Elles sont pourvues d'une membrane mince avec double contour net et contien- 
nent à l'intérieur de grandes vacuoles et parfois de petites granulations graisseuses. Elles sont solitaires ou groupées deux à deux, mais parfois on trouve des chaînettes ou des amas formés d'un petit nombre de cellules (fig. $8, a$ ).

Au bout d'une semaine, les cellules sont pour la plupart solitaires. La forme arrondie prédomine chez elles (fig. $8, b$ ).

Au bout d'un mois, les cellules qui étaient d'ordinaire solitaires
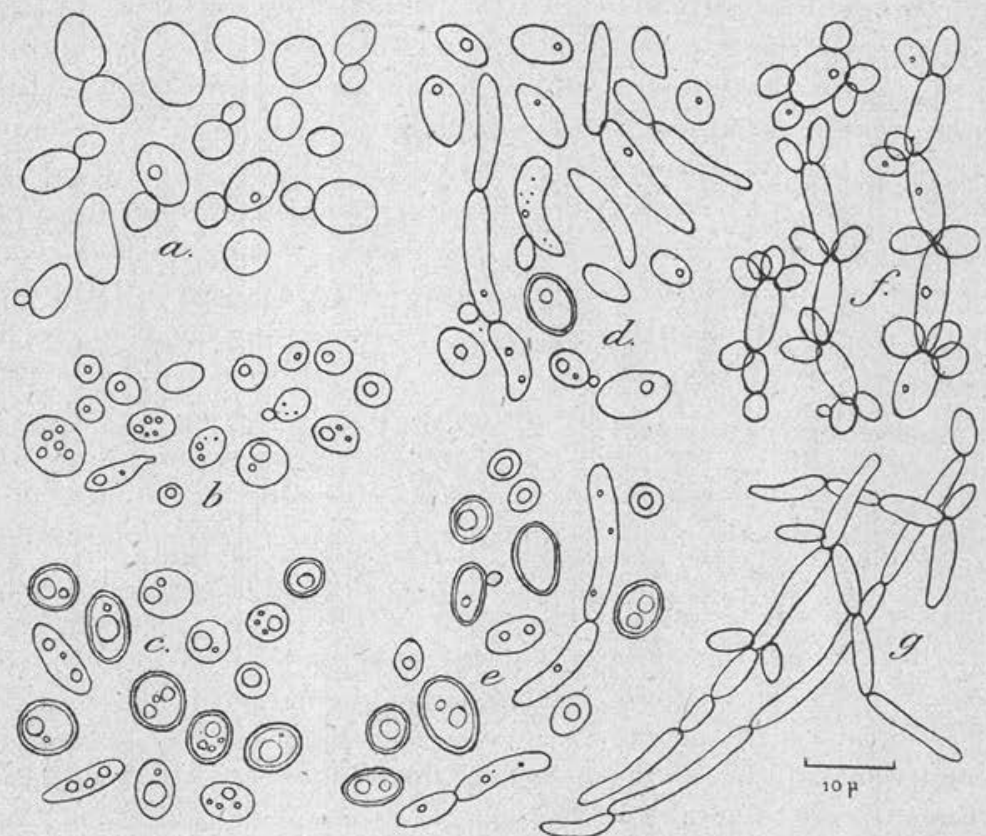

Fig. 8. - Cryptococcus de Burnier (malade C.). $a$, culture sur moût gélosé à $25^{\circ}$ au bout d'un jour; $b$, la même au bout d'une semaine; $c$, la même au bout d'un mois ; $d$, culture sur carotte à $25^{\circ}$ au bout d'un jour : $e$, la même au bout d'un mois; $f$, culture en cellule sur moût liquide au bout de 3 jours; $g$, la même au bout de 7 jours.

ont une membrane épaisse avec un double contour assez net. Leur forme est arrondie, parfois allongée. Elles contiennent des granules très volumineux (fig. $8, c$ ).

Sur tranches de earotte on trouve, outre les cellules ovoïdes ou arrondies en nombre prédominant, des cellules allongées mesurant, par exemple, $15 \mu$ sur $4 \mu$. Ces éléments ont des extrémités arrondies et forment souvent des chainettes, dès vacuoles et des granules graisseux assez nets se voient à l'intérieur (fig. $8, d$ ).

Au bout d'un mois, sur le même milieu, les cellules ont d'ordi- 
naire une membrane à double contour bien net. Les granulations augmentent de volume (fig. $8, e$ ).

Les chaînettes ou amas de cellules plus ou moins complets sont visibles surtout dans les cultures en cellule sur moût de bière liquide. Tantôt une grande cellule est entourée de plusieurs cellulesfilles, tantôt une chaînette de cellules allongées donne naissance par bourgeonnement à l'extrémité de chaque cellule à des cellules arrondies ou ovoïdes. On trouve, en outre, des filaments allongés, composés de plusieurs cellules très longues (fig. $8, f$ ).

Au bout d'une semaine, les cellules qui composent une chaînette s'allongent encore, tandis que celles qui ont poussé à leur côté se sont isolées pour la plupart. Quelques cellules-filles qui restent encore s'allongent en mème temps et forment des ébauches mycéliennes latérales (fig. $8, g$ ).

On ne trouve jamais de filaments cloisonnés comme chez les $M y-$ coderma : les extrémités de chaque cellule composant une chaînette ou un ruban sont toujours plus ou moins arrondies.

3. Aspect macroscopique de la végétation sur moût de bière. La levure forme seulement un dépôt au fond du tube ; je n'ai observé ni anneau ni voile.

4. Aspect macroscopique des cultures sur moût gélosé. - Les colonies sont d'un blanc un peu jaunâtre. Leur surface est Iisse, leurs bords sont nets.

\section{Levure de Favre}

J'ai publié en collaboration avec le docteur Favre, une étude avec figures sur cette espèce très pathogène.

Je noterai seulement ici la forme des éléments dans les cultures en cellule sur moût liquide où le développement des chaînettes et des amas est très nettement visible.

Tantôt des cellules ovoïdes et relativement grandes produisent, autour d'elles, des cellules-filles plus petites. Tantôt des cellulles allongées forment une chaînette avec des ramifications latérales composées de deux ou trois cellules allongées. Aucun filament du type Oidium.

\section{Cryptococcus Copellii Neveu-Lemaire, 1921}

Cette espèce est, comme la suivante, ordinairement de forme ovoïde ou arrondie, parfois allongée, mais elle présente en même temps des éléments filamenteux cloisonnés du type Oidium. En général, les éléments filamenteux sont rudimentaires et en petiः nombre. 
1. Origine. - Cette levure a été isolée par Copelli, en 1921, chez une femme atteinte de blastomycose de la langue et des orteils. La levure présente des éléments arrondis et ovoïdes, de dimensions variant de 5 à $12 \mu$, fortement réfringents et limités par une capsule. Elle s'est montrée pathogène pour le lapin et le cobaye.

2. Forme des cellules. - Les cellules sur moût de bière gélosé, au bout d'un jour, à $25^{\circ}$, sont d'ordinaire solitaires, mais parfois elles sont groupées deux à deux ou forment des chaînettes composées

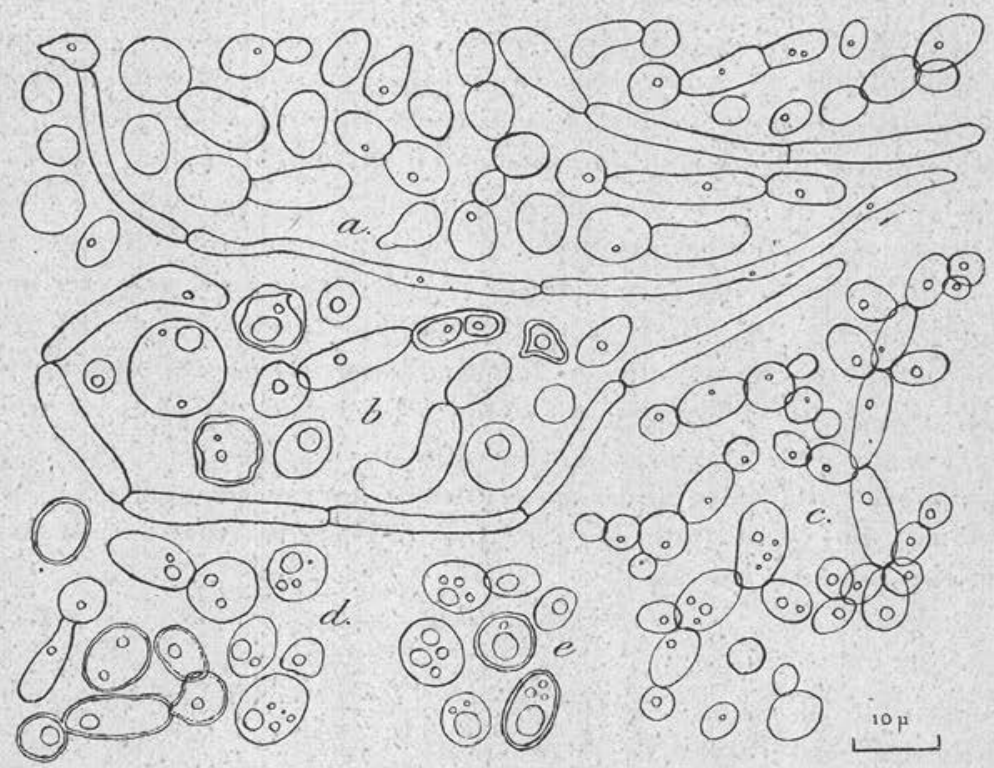

Fig. 9. - Cryptococcus Copellii. a, culture sur moût gélosé à $25^{\circ}$ au bout d'un jour; $b$, la même au bout d'un mois ; $c$, culture en cellule sur moût liquide au bout de 2 jours ; $d$, culture sur carotte à $25^{\circ}$ au bout d'un jour ; $e$, la même au bout d'un mois.

d'un petit nombre de cellules. En outre, on trouve assez rarement des filaments allongés à cloisons très espacées. Ces filaments sont composés d'ordinaire d'un petit nombre de cellules. Rarement ces filaments portent des rameaux latéraux courts. La dimension des cellules est très variable : celles qui sont sphériques ont un diamètre de 4 à $8 \mu$. Leur membrane est assez épaisse ; elles présentent à l'intérieur une ou plusieurs vacuoles remarquables et parfois des granulations graisseuses. Il en est de même pour les éléments filamenteux (fig. 9, $a$ ).

La forme des cellules ne varie pas beaucoup au bout de 3 jours. 
Mais au bout d'un mois, les éléments solitaires augmentent de volume : leur diamètre atteint souvent 10 à $12 \mu$. Ils contiennent un ou plusieurs granules relativement petits, ayant au maximum $3 \mu$ de diamètre. On voit souvent des cellules dont le contour est irrégulier. Il y a toujours dans les cultures des fragments rudimentaires de mycélium (fig. 9, b).

La forme des éléments dans les cultures sur carotte, en dehors de la dimension des granules graisseux, ne diffère pas beaucoup de celle des cultures sur moût gélosé. On observe seulement des cellules dont la membrane possède un double contour assez net, surtout dans les vieilles cultures sur carotte. Mais aucune cellule ne présente, comme chez le Cryptococcus hominis, une membrane très épaisse avec un double contour très net (fig. $9, d, e$ ).

Le développement des chaînettes ou des amas est très abondant dans les cultures en cellule sur moût liquide. Au bout de deux jours, ces cellules allongées s'unissent en chaînettes et elles donnent naissance à leur extrémité à des cellules-filles sphériques qui forment quelquefois des chaînettes secondaires. Des éléments filamenteux sont rarement visibles à la même date (fig. $9, c$ ).

3. Aspect macroscopique de la végétation sur moût liquide et sur moât gélosé. - La levure forme sur la paroi un anneau faible de couleur gris-jaunâtre, au-dessus de la surface du liquide et un dépôt épais au fond du tube.

La culture sur moût gélosé, âgée d'un mois, est épaisse ; sa surface est légèrement granuleuse et sa couleur d'un blanc-grisâtre avec une nuance faiblement jaune. Son bord est net, il s'élève remarquablement au-dessus de la surface du milieu et dessine par place une ligne dentelée.

4. Action biochimique sur les sucres. - D'après Sasagawa, cette levure provoque la formation d'un acide et de gaz avec le dextrose, le levulose, le mannose, le galactose et le maltose, mais ne produit aucune action fermentative sur le saccharose, le lactóse et le glycose.

\section{Cryptococcus de Skutetzky}

1. Origine. - Cette levure, dont la description n'a pas été publiée à cause de la mort de l'auteur, a été isolée en 1919 par Skutetzky, d'Innsbrück, d'une affection cutanée. La culture est conservée dans la mycothèque du Prof. Pribram de Vienne.

2. Forme des cellules. - Les caractères morphologiques de cette levure sont semblables à ceux de l'espèce précédente, les éléments sont d'ordinaire sphériques ou ovoïdes, mais il y a aussi des ébau- 
ches de mycélium. Sur moût gélosé, au bout d'un jour, à $25^{\circ}$, les cellules sphériques ont en moyenne un diamètre de $5 \mu$, elles renferment de grandes vacuoles, mais pas de granules. Leur membrane est relativement épaisse, mais ne montre pourtant pas de double contour net.

Il y a des cellules allongées en ruban dont l'épaisseur est de 5 ॥ et qui produisent sur les côtés quelques cellules-filles. On n'observe jamais de filaments mycéliens bien développés (fig. 10,a).

Au bout d'un mois, les cellules deviennent en général plus volu-

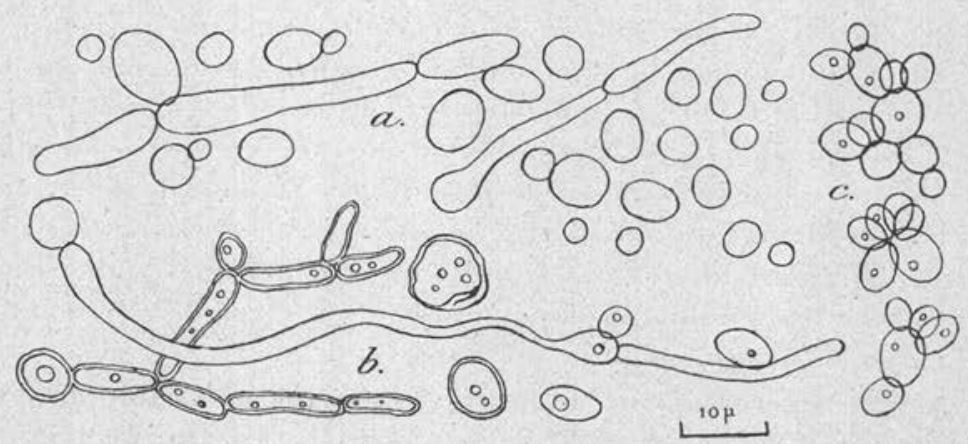

Fig. 10. - Cryptococcus de Skutetzky. $a$, culture sur moût gélosé à $25^{\circ}$ au bout d'un jour; $b$, la même au bout d'un mois ; $c$, culture en cellule sur moût liquide à $25^{\circ}$ au bout de 2 jours.

mineuses, atteignant un diamètre de $10 \mu$. Elles sont ordinairement solitaires. Les éléments filamenteux existent toujours, mais leur nombre diminue. Les cellules solitaires sont arrondies et présentent une ou plusieurs vacuoles très grandes et un petit nombre de granules. Elles sont pourvues souvent d'une membrane épaisse avec un double contour assez net (fig. $10, b$ ).

Dans les cultures en cellule sur moût liquide, au bout de deux jours, les cellules forment des amas composés de grandes cellules sphériques ou ovoïdes et de nombreuses cellules-filles groupées autour d'elles. Les éléments filamenteux ne sont observés que rarement (fig. 10, c).

3. Aspect macroscopique de la végétation sur moût de bière liquide. - Au bout de deux semaines, la levure forme un anneau grisâtre très épais sur la paroi du tube, au-dessus du liquide, et un dépôt au fond du tube.

4. Aspect macroscopique des cultures sur moât gélosé. - Les cultures de trois semaines sont d'un blane-grisâtre ou jaunâtre, 
leur surface est lisse avec une partie centrale granuleuse et des rayons très faibles du centre à la périphérie. Sur certaines colonies la surface montre des plis fins.

5. Action biochimique sur les sucres. - D'après Sasagawa, cette espèce, par la méthode des petites fermentations de Lindner, produit une action fermentative sur le dextrose, le levulose, le mannose, le galactose et le maltose, mais aucune action sur le saccharose, le lactose et le raffinose.

\section{Levure de Kartulis}

1. Origine. - Kartulis a observé en 1908 à Alexandrie (Egypte) une épidémie de blastomycose qu'il a nommée Blastomycosis glutealis fistulosa. II a isolé, dans 4 cas sur 13 malades, une levure qui, d'après lui, présente ordinairement des éléments arrondis ou ovoïdes, rarement elliptiques, et des filaments. Une de ces cultures est conservée dans la mycothèque de Vienne sous l'étiquette " Kartrick ".

2. Forme des cellules. - Cette levure présente des caractères morphologiques très variables. Dans les cultures sur moût gélosé, au bout d'un jour, à $25^{\circ}$, les cellules sont d'ordinaire arrondies ou ovoïdes, mais souvent remarquablement allongées. Leur diamètre varie beaucoup : chez les plus petites, il est de $4 \mu$, mais il atteint souvent $8 \mu$ chez les plus grandes. Les cellules allongées mesurent le plus souvent de 12 à $30 \mu$ sur 5 à $6 \mu$, mais il $\mathrm{y}$ a des filaments très longs et non cloisonnés. Les éléments sont pour la plupart solitaires, ou forment parfois des chaînettes composées de plusieurs cellules. Ces cellules sont pourwues d'une membrane assez épaisse, elles ont à l'intérieur des vacuoles et parfois un petit granule (fig. 11, $a$ ).

Au bout d'une semaine, le changement n'est pas très grand, mais il est assez remarquable au bout d'un mois. Les cellules sont souvent pourvues d'une membrane épaisse et elles ont à l'intérieur un ou plusieurs granules plus volumineux. On trouve des cellules avec un contour irrégulier. En outre, il y a des ébauches de mycélium et un petit nombre de filaments mycéliens véritables avec des cloisons. Ces filaments ne montrent pourtant pas de ramifications ni de sporulation latérale bien nettes (fig. 11, b).

La formation des filaments ou des amas de cellules plus ou moins bien développés s'effectue dans les cultures en cellule sur moût liquide ou sur eau de pomme de terre. On trouve sur moût liquide des amas de grandes cellules sphériques accompagnées de plusieurs 
cellules-filles et des chaînettes de cellules un peu allongées avec des ramifications compliquées.

Il y a aussi des cellules plus ou moins filamenteuses qui poussent de courtes branches latérales composées de quelques cellules allongées. Ces rameaux produisent encore à leurs extrémités-des cellules-filles sphériques. C'est tout à fait l'ébaúche d'un Monilia. Il y a encore des filaments du type Oidium, mais en général on en trouve très peu (fig. 11, $c$ ).

Sur eau de pomme de terre, on observe en plus des cellules soli-

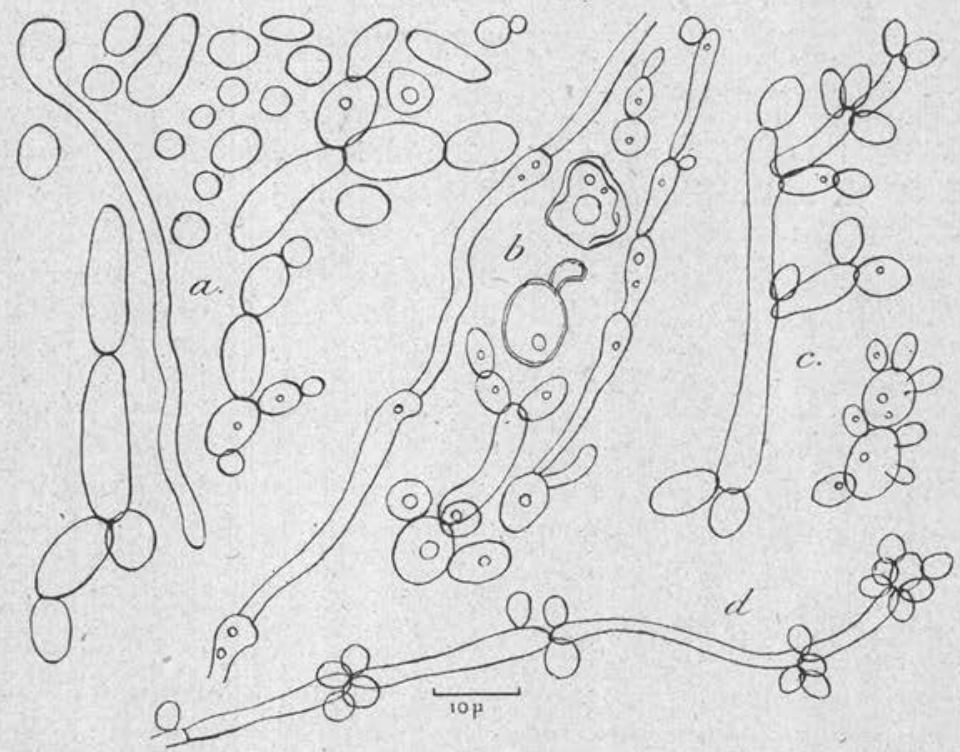

Pig. 11. - Levure de Kartulis. $a$, culture sur moût gélosé à $25^{\circ}$ au bout d'un jour; $b$, la même au bout d'un mois ; $c$, culture en cellule sur moût liquide au bout de 2 jours; $d$, culture sur eau de pomme de terre au bout d'un mois.

taires de diamètre variable et des filaments rudimentaires, composés de quelques cellules très allongées. Il se produit par bourgeonnement, surtout aux extrémités des cellules, des éléments secondaires arrondis ou ovoïdes (fig. $11, d$ ). Aucune ramification latérale n'est visible.

5. Aspect macroscopique de la végétation sur moût liquide. - Au bout de deux semaines, la levure forme un anneau gris-jaunâtre très épais sur la paroi du tube au-dessus de la surface du liquide ; il se transforme en un voile au bout d'un mois. La levure forme en même temps un dépôt au fond du tube. 
6. Aspect macroscopique des cultures sur moût gélosé. - Les colonies sont très épaisses et crémeuses, leur couleur est brunâtre. La surface des vieilles cultures présente des plis épais, sinueux et serrés.

7. Action biochimique sur les sucres. - D'après Sasagawa, cette levure produit un acide et des gaz avec le dextrose, le levulose, le mannose, le galactose, mais elle ne présente aucune action fermentative avec le saccharose, le maltose, le lactose et le raffinose.

\section{III. - Genre Monilia}

Lindau a conservé, dans sa classification des Hyphomycètes, les deux genres : Oospora et Monilia, mais leur distinction reste incertaine. D'après lui, le genre Oospora Wallroth, 1833, contient des champignons filamenteux dont les conidies naissent à la manière des Oidium, par fragmentation des filaments et en même temps forment une chaînette portée par un conidiophore qui ne se distingue pas nettement du mycélium. Dans le genre Monilia Persoon, 1880, les conidies naissent sur un conidiophore plus ou moins distinct. Dans ces deux genres le mycélium se développe très bien et forme une couche compacte.

Vuillemin (1911) a objecté avec raison que la définition du genre Oospora manque de base précise ; il dit que ce genre peut contenir des champignons arthrosporés du type Oidium et des espèces répondant à la cractéristique des Monilia. Quant au genre Monilia Persoon, il a semblé à Vuillemin inacceptable et il a cherché le prototype du genre Monilia dans le M. aurea Gmelin (Syst. Nat., 1791).

Il a séparé des Thallosporés et des Oidium le genre Monilia qu'il définit de la manière suivante : " Le genre Monilia se distingue des Conidiosporés et des Arthrosporés : c'est un type de Blastosporés. Il se distingue des Blastomycètes (sensu stricto) chez lesquels il n'existe que des globules bourgeonnants. Ceux-ci ne se montrent chez les Blastosporés que dans la portion du thalle qui fonctionne comme spore sans perdre son activité végétative, tandis que les parties purement végétatives gardent la structure de filaments diffus ou associés en stroma " (loc. cit., p. 139-140).

Nous adopterons la définition de Vuillemin et rangerons dans le genre Monilia ainsi compris tous les Blastosporés qui produisent un mycélium bien développé et des éléments sphériques bourgeonnants.

Nous n'acceptons done pas les genres provisoires de de Beurmann et Gougerot, Zymonema et Parendomyces. 
Le genre Zymonema manque d'un caractère morphologique qui permettrait d'en faire un genre valable. Nous n'avons pas eu l'occasion d'étudier le parasite de Gilchrist, mais, d'après la description et les figures de Gîlchrist et de de Beurmann et Gougerot, ce parasite ne présente que des filaments oïdiens et des formes levures (cellules sphériques ou elliptiques bourgeonnantes). Son seul caractère un peu particulier est de montrer des filaments composés de cellules irrégulières et de grandeur variable.

La définition du genre Parendomyces de de Beurmann et Gougerot ne repose que sur des caractères négatifs. Il renfermerait des champignons dont les caractères morphologiques sont tout à fait pareils à ceux des Endomyces, mais qui ne produisent pas d'asques. Pour moi, ces espèces ne sont que des Monilia dont les chlamydospores sont parfaitement développées.

Les deux genres de de Beurmann et Gougerot peuvent done être incorporés sans inconvénient dans le genre Monilia.

Je n'ai étudié qu'une seule espèce de Monilia : celui de Foulerton, je ne peux done pas ici chercher des types parmi les Monilia.

J'ai encore une autre espèce qui pourrait être classée dans ce genre : c'est la levure conservée dans la mycothèque du prof. Pribram, à Vienne, sous l'étiquette de levure de Curtis : c'est probablement le Saccharomyces cutaneus tumefaciens Curtis qui aurait perdu la capacité de donner des asques. Je l'ai exclu de mon étude.

\section{Saccharomyces tumefaciens album Foulerton, 1900}

\section{(Monilia de Foulerton)}

1. Origine. - Foulerton a isolé, en 1900 , une levure dans deux cas de pharyngite, mais il n'a pas précisé si elle était l'agent causal de la maladie. Toutefois cette levure s'est montrée assez fortement pathogène pour le lapin, le cobaye, le rat et la souris.

D'après Foulerton, cétte levure, au bout de 24 heures, présente ordinairement des éléments isolés qui renferment des vacuoles et des granules. Le diamètre des cellules est de 3 à $4 \mu$. Il a trouvé des " pseudomycélium " seulement dans les tissus. Cette espèce est conservée dans la mycothèque de Vienne.

2. Forme des cellules. - Sur moût de bière gélosé, au bout d'un jour, à $25^{\circ}$, les cellules tantôt sont isolées et de forme arrondie ou ovoïde ; tantôt elles forment des chapelets composés d'un petit nombre de cellules ovalaires ; tantôt enfin elles constituent des filaments mycéliens simples ou ramifiés, donnant naissance à leurs extrémités ou latéralement à des chaînettes de cellules ovoïdes. 
La longueur des cellules qui composent les filaments est en moyenne de 10 à $20 \mu$, mais elle peut dépasser beaucoup ces dimensions ; les extrémités de ces articles sont arrondies. Des filaments cloisonnés, du type Oidium, se montrent plus tard dans les cultures. Les cellules isolées ou en chapelet ont un diamètre de 3 à $8 \mu$; elles contiennent ordinairement une ou plusieurs, vacuoles. La membrane possède un double contour plus ou moins net (fig. 12, $a$ ).

Les modifications des caractères morphologiques au bout d'une

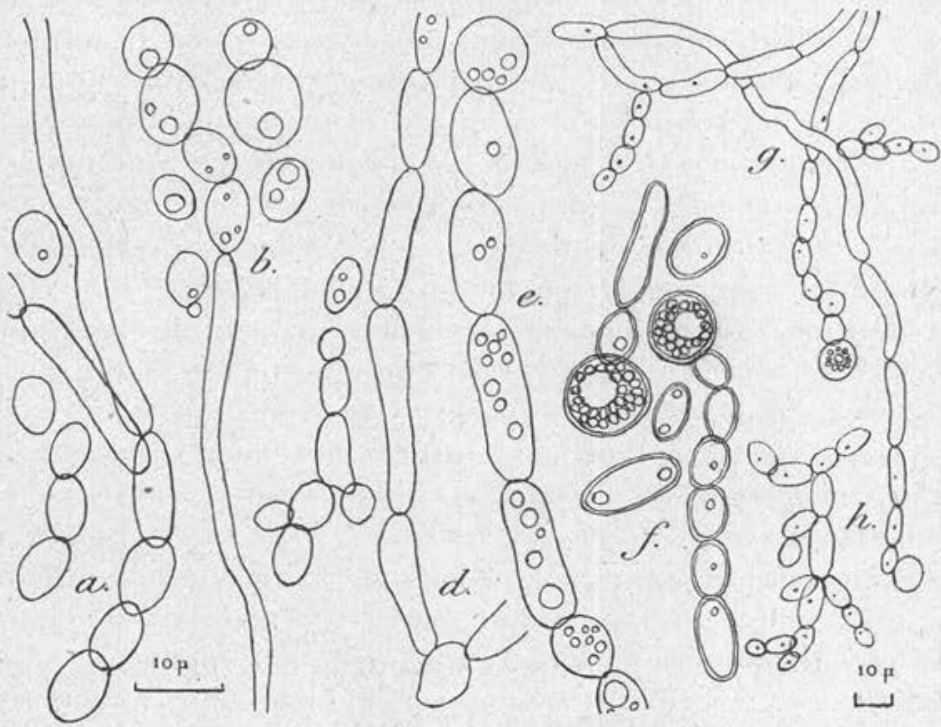

Fig. 12. - Monilia de Foulerton. $a$, culture sur moût gélosé à $25^{\circ}$ au bout d'un jour ; $b$, la même au bout de 4 jours; $d$, culture sur carotte à $25^{\circ}$ au bout d'un jour ; $e$, la même au bout de 4 jours ; $f, g$, la même au bout d'un mois ; $h$, culture sur eau de pomme de terre au bout d'un mois.

semaine et au bout d'un mois, sur les mêmes milieux, consistent en ceci : les cellules isolées augmentent de volume et se chargent de granulations graisseuses. On voit de grandes cellules qui ont de 10 à $12 \mu$ de diamètre. En outre, on trouve quelquefois des filaments cloisonnés par place comme chez les Mycoderma (fig. 12, $f, g$ ).

En résumé, les filaments mycéliens ne se développent pas très bien dans les cultures sur moût gélosé. Au contraire, sur carotte, on trouve, même au bout d'un jour, des filaments bien développés. Ils montrent souvent des ramifications dichotomiques. En outre, on voit des cellules isolées ou en chapelet (fig. 12, $d, e$ ).

Les caractères morphologiques des cellules sont plus frappants au 
bout de 4 jours sur les mêmes milieux. Chaque cellule contient à l'intérieur plusieurs granules graisseux assez grands et très réfringents. Les chlamydospores commencent à se former à l'extrémité du chapelet. Les cellules solitaires augmentent en général de volume, en même temps leur membrane s'épaissit et présente un double contour assez net (fig. 12,e).

Au bout d'un mois, la forme des éléments est à peu près la même qu'au bout de 4 jours. Mais, à cette époque, on est frappé de voir de nombreuses cellules qui présentent un aspect très particulier. $\mathrm{Ce}$ sont les chlamydospores. Elles sont d'ordinaire rondes, d'un diamètre de $10 \mu$ et pourvues d'une membrane épaisse avec un double contour net. Elles contiennent à l'intérieur une grande vacuole ronde un peu excentrique et de nombreux granules assez volumineux et très réfringents, serrés les uns contre les autres en rangées concentriques. Ces granules disparaissent sous l'influence de l'iodolactophénol; ils ne se colorent pas par le soudan III (fig. 12, $f$ ).

3. Aspect macroscopique de la végétation sur moût de bière liquide. - La levure forme un dépôt épais et un anneau très faible au bout de deux semaines. Cet anneau disparaît au bout d'un mois.

4. Aspect macroscopique des cultures sur moût gélosé. - Lés colonies sont d'un blanc-grisêtre avec une nuance jaurne, leur surface montre des plis sinueux et serrés.

5. Actions biochimiques sur les sucres. - D'après Sasagawa, cette levure provoque la formation d'un acide et de gaz avec le dextrose, le levulose, le mannose et le galactose ; elle n'a aucune action fermentative sur le saccharose, le maltose, le lactose et le raffinose.

6. Température optima. - D'après Foulerton, cette espèce se développe mieux à $37^{\circ}$ qu'à $22^{\circ}$.

\section{RÉsumé}

Dans cette étude, j'ai décrit une nouvelle espèce de Debaryomyces provenant d'une dermatomycose : D. Burnieri.

En outre, j'ai fait une révision de quelques levures anascosporées et des quelques champignons voisins des levures, considérés les uns et les autres comme pathogènes.

Le terme courant de blastomycète est inexact et je répartis les parasites autrefois nommés ainsi entre deux genres : Cryptococcus et Monilia. Avec Vuillemin, je rejette le genre Oospora dont la définition manque de base précise. Le genre Cryptococcus renferme, outre des levures sphériques, ovoïdes ou elliptiques (groupe $a$ ), d'autres formes possédant des ébauches de mycélium (groupe $b$ ).

Les genres provisoires de de Beurmann et Gougerot, Atelosaccha- 
romyces et Parasaccharomyces, ne sont que des formes de Cryptococcus et les deux autres genres créés par eux : Zymonema et Parendomyces ne sont que des Monilia.

Entre les Cryptococcus possédant des ébauches de filaments et les Monilia, il y a des formes de transition.

J'ai établi quelques divisions parmi les Cryptococcus à cellules sphériques ou un peu allongées d'après leurs caractères morphologiques.

$$
*
$$

En terminant ce travail, j'exprime toute ma reconnaissance à M. le prof. Guilliermond, qui m'a fait connaître les levures, et à $\mathrm{M}$. le $\mathrm{D}^{\mathrm{r}}$ Langeron auprès de qui j'ai trouvé des encouragements et des conseils.

\section{BIBLIOGRAPHIE}

De Beurmann et Gougerot. - Les exascoses. Tribune méd., 1909, p. 501-524.

Blanchard, Schwarz et Binot. - Sur une blastomycose intrapéritonéale. Arch. de Parasitologie, VII, 1903, p. $489-507$, pl. VI.

Buschкв. - Die Blastomykose. Bibliotheca medica, Stuttgart, 1902.

Busse. - Ueber Saccharomycosis hominis. Virchow's Archiv, CXL, 1895.

Copell. - Sopra un caso di Blastomicosi. Journ. d. malattie ven. e. d. pelle, Fasc. IV, 1912.

Favre et Ota. - Note sur une levure cutanée pathogène. C. R. Soc. biol., LXXXVIII, 15 janvier 1923, p. 222.

Flu et Wónsdreght. - Een geval Blastomycose van het Centraalzenuwustelsel. Meded. v. d. burgerl. Geneesk. dienst in Nederl. Indie, VI, 1918.

Fontoxnont et Boucher. - Contribution à l'étude des mycoses de Madagascar. Ann. de dermatol. et syphil. (VI), IV, No 4, 1923.

Foulerton. - On the pathologic action of Blastomyces. Journ. of Pathol. and Bacteriol., VI, 1900 , p. $37-63$, pl. IV.

Freeman et Weidman. - Cystic blastomycosis of central gray matter, caused by Torula histolytica Stoddard and Cutler. Arch, of Neurol and Psych., IX, 1923, p. 222.

Govgerot et Gancea. - Epidermomycose due à un parasite levuriforme. Bull. Soc. dermat. et syphil., XXV, 1914, p. 335-339.

Kartulis. - Chronik Fistel an der Glutealgegend. Uber Blastomycosis glutealis fistulosa. Zeitschr. für Hyg., LXIV, 1909.

Lindau. - in Rabenhorst's Kryptogamen Flora, VIII, Pilze, 1907.

OтA (M.). - Cinq levures du genre Debaryomyces considérées comme pathogènes. Ann. de parasitologie, I, 1923, p. 124-136.

SaSagawa. - Zur Systematik pathogener und parasitischer Hefen. Centralbl. für Bakt., I Abt., Orig., LXXXVIII, 1922.

Stoddard et Cutler. - Torula infection of man. Monograph No 6, lnst. Rockefeller, New-York, 1916.

Vuillemin. - Différence fondamentale entre le genre Monilia et les genres Scopulariopsis, Acmosporium et Catenularia. Bull. Soc. mycol. de France, XXVII, 1911 , p. $137-152$.

Laboratoire de Parasitologie de la Faculté de médecine de Paris. 